\title{
O ECOLOGISMO DOS POBRES E O RACISMO AMBIENTAL: REFLEXÕES SOBRE SOCIEDADE E NATUREZA PARA UMA EDUCAÇÃO AMBIENTAL CRÍTICA
}

\section{THE ENVIRONMENTAL OF THE POOR AND ENVIRONMENTAL RACISM: REFLECTIONS ON SOCIETY AND NATURE FOR A CRITICAL ENVIRONMENTAL EDUCATION}

Viviane Camejo Pereira ${ }^{1}$

Claudemira Vieira Gusmão Lopes ${ }^{2}$

\begin{abstract}
Resumo
O objetivo deste ensaio é apresentar a contribuição do ecologismo dos pobres e do racismo ambiental para a construção de uma perspectiva crítica da relação sociedade-natureza no contexto da Educação Ambiental. Parte-se de que a Educação Ambiental crítica é um campo propício para diálogos críticos sobre a problemática socioambiental em espaços escolares e não escolares. Por meio de uma revisão bibliográfica, argumenta-se que as populações tradicionais do campo, das águas e das florestas e as populações economicamente vulneráveis nas periferias das grandes cidades muitas vezes são afastadas da convivência com um ambiente conservado. A exploração e degradação da natureza e relações sociais desiguais são inerentes aos conflitos socioambientais que expressam um modelo de desenvolvimento insustentável. Debates sobre a relação sociedade-natureza focados em propostas de reciclagem, consumo consciente e outras medidas paliativas sugeridas por várias correntes ecológicas, não são suficientes para fazer o enfrentamento à escassez de recursos, à pobreza e a destruição acelerada da natureza. A relação do ser humano com a natureza é também reflexo das relações sociais. Assim, propõem-se uma Educação Ambiental crítica construída a partir do diálogo interdisciplinar com as perspectivas do ecologismo dos pobres e o racismo ambiental como forma de contextualizar o debate ambiental nas relações sociais.
\end{abstract}

Palavras-chave: Problemática socioambiental; Justiça ambiental; Vulnerabilidade socioeconômica.

\begin{abstract}
This essay aims to present the contribution of the environmentalism of the poor and Environmental Racism in constructing a critical perspective of the society-nature relationship in the context of Environmental Education. Critical Environmental Education is a favorable field for critical dialogues about the socio-environmental issues in school and non-school spaces. A literature review argues that the
\end{abstract}

\footnotetext{
*Artigo Original: Recebido em 17/10/2021 - Aprovado em 05/11/2021.

${ }^{1}$ Bióloga, Mestra e Doutora em Desenvolvimento Rural, Professora do Curso de Licenciatura em Educação do Campo- Ciências da Natureza, Universidade Federal do Paraná, Setor Litoral (UFPR Litoral), Matinhos/PR, Brasil. e-mail: vivianecamejop@gmail.com ORCID: https://orcid.org/0000-0002-6614-8679 (autor correspondente)

${ }^{2}$ Bióloga, Mestra em Ciência do Solo e Doutora em Ciências Agronômicas, Professora do Curso de Licenciatura em Educação do Campo - Ciências da Natureza e do Programa de Pós-Graduação em Rede Nacional para o Ensino das Ciências Ambientais (Profciamb), UFPR Litoral, Matinhos /PR, Brasil. e-mail: clauvieiragusmao@gmail.com ORCID: https://orcid.org/0000-0001$5710-5434$
} 
traditional populations of the countryside, waters, and forests, and economically vulnerable populations on the outskirts of large cities have their house banished from the so-called conserved environments. The exploitation and degradation of nature and unequal social relations inherent socio-environmental conflicts that express an unsustainable development model. Debates about the society-nature relationship focused on recycling proposals, conscious consumption, and other palliative measures suggested by various ecological currents are not enough to face the scarcity of resources, poverty, and the accelerated destruction of nature. The human being's relationship with nature is also a reflection of social relationships. Therefore, we propose a critical Environmental Education built from an interdisciplinary dialogue, considering the perspectives of the ecologism of the poor and Environmental Racism, to contextualize the environmental debate in social relations.

Keywords: socio-environmental issues; environmental justice; socioeconomic vulnerability.

\section{Introdução}

Estamos vivendo um período em que é urgente a realização de reflexões sobre a relação sociedadenatureza a partir das relações sociais da própria sociedade. A crise ambiental já apontada por autores como Leff (2012) e Fernandes e Sampaio (2012) necessita de um olhar crítico e que aponte para a transformação das relações sociais, de forma que se possa viver de forma mais integrada e harmoniosa com a natureza. Esta transformação passa pela construção de processos e aprendizagens que incluam as pessoas na natureza e proporcionem a transformação da realidade socioambiental.

No debate ético sobre a questão ambiental, reforçase que as pessoas que exerçam o papel de educadores e educadoras, possam contextualizar a problemática socioambiental na desigualdade social, étnica e racial despertando a partir da Educação Ambiental olhares críticos que localizem o ser humano na natureza. A relação que as pessoas têm com o ambiente reflete a relação das pessoas em sociedade. Assim, o debate ambiental está imerso nas relações sociais. Segundo Fernandes e Sampaio (2008):

Disse-se que os problemas ambientais surgem do modo como a sociedade relaciona-se com a natureza. O que faltou dizer é que essa relação com a natureza nada mais é do que parte da relação que se estabelece entre as sociedades e entre os indivíduos. (FERNANDES; SAMPAIO, 2008, p. 89).
Infere-se a necessidade da análise dos processos de desenvolvimento em uma perspectiva crítica, atenta a injustiça ambiental sofrida por diversas comunidades do campo e da cidade, sintoma de processos de desenvolvimento desiguais e insustentáveis. Para contribuir nestas reflexões apresenta-se o ecologismo dos pobres (TILIO NETO, 2009) ${ }^{\mathrm{i}}$ e/ou movimento por justiça ambiental (MARTÍNEZ-ALIER, 2009) e o racismo ambiental (ACSELRAD, 2002; PACHECO; FAUSTINO, 2013) como campos do debate socioambiental que podem contribuir para uma Educação Ambiental crítica.

As macrotendências político-pedagógicas da Educação Ambiental propostas por Layrargues e Lima (2014) convergem com as correntes do ecologismo apresentadas por Martínez-Alier (2009). Pode-se inferir as seguintes correlações: a corrente culto ao silvestre de Martínez-Alier (2009) dialoga com a macrotendência conservacionista, a corrente o evangelho da ecoeficiência com a macrotendência pragmática e a corrente do ecologismo dos pobres com a Educação Ambiental crítica. Loureiro e Layrargues (2013) afirmam a pertinência da articulação entre a justiça ambiental e a Educação Ambiental crítica devido a forma como estes campos caracterizam a crise ambiental. É a partir destas correlações e da importância da articulação entre a Educação Ambiental e o ecologismo dos pobres ou movimento por justiça ambiental, incluindo também a perspectiva do racismo ambiental que este ensaio propõe o embasamento do debate sobre a relação sociedade-natureza na Educação Ambiental crítica. O estudo envolveu a revisão bibliográfica, com a inclusão de autores considerados importantes para o debate proposto. Também foram buscados no Google Acadêmico textos relevantes dentro da 
temática proposta que continham o termo "Educação Ambiental crítica".

Optou-se por organizar o texto em cinco seções além desta introdução e das referências. Na seção Abordagens sobre a problemática e a crise (socio) ambiental e o desenvolvimento são apresentados aspectos gerais que permeiam a problemática socioambiental e o desenvolvimento. Em O ecologismo dos pobres e o racismo ambiental e sua contribuição na abordagem sobre a relação sociedade-natureza, pretende-se demonstrar a relevância destas perspectivas para a construção da Educação Ambiental crítica. Já na seção A educação ambiental crítica como espaço de diálogo sobre a relação sociedade-natureza parte-se de que a Educação Ambiental a partir de uma perspectiva crítica é necessária para um debate sobre a relação sociedade-natureza em espaços escolares e não escolares que contribuam para a transformação da realidade socioambiental.

\section{Abordagens sobre a problemática e a crise (socio)ambiental e o desenvolvimento}

A crise ambiental que se manifestou mais intensamente a partir dos anos de 1960 trouxe à tona a "irracionalidade ecológica dos padrões dominantes de produção e consumo" (LEFF, 2012, p. 16). Para Fernandes e Sampaio (2012) a problemática ambiental relaciona-se com o modo de vida das sociedades ocidentais no que tange a produção e consumo, tendo também aspectos sociais e econômicos (FERNANDES; SAMPAIO, 2012). Para os autores, "A definição de problemática ambiental, portanto, é uma definição diretamente ligada às atividades sociais que incidem sobre a natureza" dessa forma, uma problemática socioambiental (FERNANDES; SAMPAIO, 2012, p. 89).

A degradação ambiental é sintoma de uma crise civilizatória "marcada pelo modelo de modernidade regido pelo predomínio do desenvolvimento da razão tecnológica sobre a organização da natureza" (LEFF, 2012, p. 17). Para Fernandes e Sampaio (2012, p. 89) a crise do paradigma atual que a sociedade vivencia é "uma crise da relação sociedade/natureza, e as suas causas estão no modo de vida centrado na ideia de progresso e colonização". No debate ambiental, a colonialidade contribui para a compreensão da divisão sociedade e natureza criada pelo pensamento colonial moderno, fruto de "processos identitários culturais de dominação e de exploração" (TRISTÃO; VIEIRAS, 2017, p. 104). O debate sobre colonialidade e questão ambiental é importante na problematização do racismo ambiental como o fazem Pacheco e Faustino (2013).

Nas periferias das grandes cidades, muitas comunidades em situação de vulnerabilidade socioeconômica sofrem com os problemas socioambientais urbanos, enfrentando situações de conflitos socioambientais. Muitas destas comunidades também enfrentam a condição de viver em meio à degradação ambiental, em situação de racismo ambiental em que "as injustiças sociais e ambientais que recaem de forma implacável sobre grupos étnicos vulnerabilizados e sobre outras comunidades, discriminadas por sua 'raça', origem ou cor" (PACHECO, 2014?). A discriminação tratada por Pacheco (2014?) tem estreita relação com a condição socioeconômica destes sujeitos, situando este debate no ecologismo dos pobres ou movimento por justiça ambiental desenvolvido por MartínezAlier (2009) que será tratado na próxima seção deste trabalho.

O Brasil é um país constituído por uma diversidade de sujeitos, dentre eles os povos e comunidades tradicionais, camponeses, agricultores familiares, dentre vários outros. Os povos e comunidades tradicionais são "grupos culturalmente diferenciados e que se reconhecem como tais" tendo formas próprias de organização social e de organização do território (BRASIL, 2007, Art. 3o, I). Estes povos mantêm relações intrínsecas com seus territórios, tratados aqui como territórios do campo, das águas e das florestas. Muitos destes sujeitos vivem em contextos específicos cuja relação com a natureza é essencial para o desenvolvimento de suas atividades econômicas e manutenção de seus modos de vida. Nos projetos de desenvolvimento, não é incomum o desencontro de visões de mundo, quando grupos externos a estas comunidades lhes impõem visões de mundo que não são aceitáveis por elas, divergindo da forma de como se apropriam e vivem na natureza. Em muitos destes casos estabelecemse situações de conflitos socioambientais, sejam eles distributivos, espaciais ou territoriais ${ }^{\mathrm{ii}}$ (ZHOURI; LASCHEFSKI, 2010).

Os povos culturalmente e etnicamente diferenciados em relação à sociedade urbana moderna ocidental não necessariamente vivem de acordo com os mesmos hábitos de consumo 
das grandes cidades, nem sob as mesmas lógicas econômicas que imperam na sociedade moderna ocidental e nos países considerados desenvolvidos. Assim, infere-se a importância da descolonização do pensamento nas ciências, principalmente as ambientais, como forma de promover e orientar processos abrangentes e integrativos para a sustentabilidade no desenvolvimento. Para Ferreira (2012, p. 14) "O campo de Ciências Ambientais mostra-se fecundo para a descolonização epistêmica" e "Reconhece a importância geopolítica e a espacialidade na construção do conhecimento desses países colonizados, buscando criar caminhos que enriqueçam o saber sistêmico e endógeno de cada territorialidade."

Parte-se do pressuposto de que a Educação Ambiental possa ser trabalhada relacionando os contextos locais aos globais. Abordagens como as que responsabilizam os indivíduos por suas práticas, sem a devida análise crítica do contexto socioeconômico a que estas pessoas estão submetidas, muitas vezes não contribuem para repensar a relação sociedadenatureza. Até que ponto faz sentido culpabilizar unicamente os indivíduos pela crise ambiental, por seus hábitos de consumo e desperdício de água, em comunidades em que as pessoas não consomem nem o mínimo para garantir sua sobrevivência e não possuem saneamento básico? Esta forma de abordagem é muitas vezes distante da realidade local nos países considerados em desenvolvimento. Para relocalizar a sociedade na natureza é preciso aproximar-se da realidade socioeconômica e ambiental das comunidades. Descolonizar o pensamento no que tange à problematização sociedade-natureza envolve a valorização das práticas e as visões de mundo das populações tradicionais que contribuem para a sustentabilidade, já que muitas destas populações têm convivido de forma sustentável em seus territórios, e dependendo da conservação ambiental para sua sobrevivência e manutenção das suas práticas. Inclui também a importância da sustentabilidade socioambiental com reflexões que partam da concepção de que o ser humano faz parte da natureza (FERREIRA, 2019). O ser humano é "parte integrante da natureza e manifesta uma relação claramente orgânica, dialética e ontológica, que envolve uma simbiose entre os entes" (SOUZA, 2015, p. 156).
3 A separação sociedade-natureza no pensamento ambiental e o desenvolvimento

O modelo preservacionista de conservação ambiental, baseado no modelo norte-americano em que os parques serviam para o "desfrute da população das cidades norte-americanas que, estressadas pelo ritmo crescente do capitalismo industrial, buscavam encontrar no mundo selvagem" (DIEGUES et al., 2000) parte de que toda a

[...] relação entre sociedade e natureza é degradadora e destruidora do mundo natural e selvagem - a wilderness norteamericana - não havendo distinções entre as várias formas de sociedade (a urbano industrial, a tradicional, a indígena, etc.). (DIEGUES et al., 2000, p. 4) ${ }^{\mathrm{iii}}$.

Esta concepção ao ser implementada no Brasil deparou-se com a presença de diversas comunidades habitando territórios que foram posteriormente destinados à proteção ambiental (DIEGUES; NOGARA, 2005). Gómez-Pompa e Kaus (2000, p. 127) afirmam que as perspectivas clássicas de conservação partem de que há uma oposição entre as "ações humanas e o bem-estar do meio ambiente natural."

A ideia do ser humano dominador da natureza, concepção positivista preponderante na ciência moderna, influenciando também o pensamento ambiental, permeia projetos de desenvolvimento em que a valoração da natureza por determinados setores econômicos, se dá em diversos casos, em detrimento das relações sustentáveis que comunidades no campo e na cidade mantêm com este ambiente. Assim, a transformação da natureza em mercadoria evidencia lógicas e visões de mundo distintas em que o olhar dos setores economicamente dominantes se sobrepõe sobre a cultura dos povos em seus territórios. Esse processo remete à necessidade de um olhar sobre a colonialidade do pensamento ambiental. Para Tristão e Vieiras (2017, p. 104) "A colonialidade nos ajuda a compreender que as dicotomias criadas pelo pensamento colonial moderno impõem um modelo dissociativo da sociedade com o meio ambiente, uma relação de controle dos povos, dos territórios e das naturezas culturas." Essa colonialidade se acentua quando, por exemplo, são importadas metodologias 
de trabalho e concepções que não dialogam com os contextos locais, impondo visões de mundo que perpetuam a desigualdade social, étnica e racial e causam a expulsão das comunidades de seus territórios. As injustiças ambientais fundamentam a problematização do ecologismo dos pobres (MARTÍNEZ-ALIER, 2009) e do racismo ambiental (ACSELRAD, 2002; PACHECO; FAUSTINO, 2013).

Para Souza (2015), as forças hegemônicas da sociedade produzem muitas vezes discursos centrados na preservação dos recursos naturais para que não haja a inviabilização das atividades econômicas no futuro, por exemplo as atividades industriais e produção de commodities. No âmbito contra-hegemônico, prioriza-se a apropriação da natureza por seu valor de uso, como forma de manter "a reprodução e sobrevivência de determinados grupos sociais atrelados culturalmente a estes espaços.” (SOUZA, 2015, p. 159). Estas forças permeiam o debate sobre desenvolvimento incidindo diretamente nas relações sociais, econômicas e culturais da sociedade.

A concepção de desenvolvimento que orienta a visão de mundo da sociedade moderna tem influência na ideia de progresso (BRESSER-PEREIRA, 2014) ${ }^{\text {iv }}$. Para Dupas (2007, p. 73), o progresso “discurso dominante das elites globais, traz também consigo exclusão, concentração de renda, subdesenvolvimento e graves danos ambientais, agredindo e restringindo direitos humanos essenciais". Este progresso tem acentuado os problemas sociais e as contradições, conforme será explicitado em alguns dados a seguir.

De acordo a Pesquisa Nacional por Amostra de Domicílios (PNAD) Contínua divulgada no final de agosto pelo IBGE, os trabalhadores informais no primeiro trimestre de 2021 somaram 35,6 milhões de pessoas, perfazendo uma taxa de 40,6\% (BARROS, 2021). A taxa de desocupação no primeiro trimestre encerrado em junho de 2021 foi de 14,1\%, atingindo 14,4 milhões de pessoas (BARROS, 2021). Apesar do grande número de desempregados, no Brasil, no último ano, o número de bilionários aumentou de 45 para 65 e a riqueza somada por eles cresceu $71 \%$ durante a pandemia (BRASIL DE FATO, 2021) ${ }^{\mathrm{v}}$.

Ao mesmo tempo, segundo o inquérito populacional realizado pela Rede Brasileira de Pesquisa em Soberania e Segurança Alimentar (Rede PENSSAN) para analisar a Insegurança Alimentar no Brasil no contexto da pandemia da Covid-19: "Do total de 211,7 milhões de brasileiros(as), 116,8 milhões conviviam com algum grau de Insegurança Alimentar e, destes, 43,4 milhões não tinham alimentos em quantidade suficiente e 19 milhões de brasileiros(as) enfrentavam a fome" (REDE PENSSAN, 2021, p. 10). Em relação a questão ambiental, dados do sistema DETER do Instituto de Pesquisas Espaciais (Inpe) publicados em junho de 2021 revelam que houve um aumento de $66,7 \%$ na área com alertas de desmatamento entre maio de 2020 e maio de 2021 com recordes de queimadas na Amazônia e Cerrado (MOTA, 2021). Em 2021 a escassez hídrica no Brasil tem influenciado o aumento da inflação diminuindo inclusive o poder de compra de alimentos, o racionamento de água, o aumento do custo da energia elétrica para as famílias, custo maior para indústria o que pode impactar o preço de produtos e perda do PIB do agronegócio (GERBELLI, 2021). Estes dados demonstram que apesar do Brasil ter sido considerado em 2021 a $13^{\mathrm{a}}$ economia mundial (FERRARI, 2021), isso não contribuiu para o combate à degradação ambiental e nem acabou com a fome e tantos outros problemas socioambientais e econômicos. Nesse sentido cabe a problematização sobre até que ponto a eficiência tecnológica seria capaz de resolver os problemas ambientais. Essa problematização será demonstrada na próxima seção deste ensaio.

É preciso uma perspectiva ambiental do desenvolvimento que de acordo com Leff (2012) supere as políticas econômicas, tecnológicas e educativas que prevalecem na sociedade de forma a orientar "os processos produtivos para o aproveitamento do potencial ambiental de cada região, fundado na articulação de seus sistemas ecológicos, tecnológicos e culturais, para satisfazer as necessidades básicas e melhorar a qualidade de vida da população" (LEFF, 2012, p. 201). O desenvolvimento precisa evidenciar "os valores, as crenças e diferentes modos de vida, sobretudo de comunidades tradicionais, configurando-se numa proposta paradigmática não só de cunho científico como também de cunho cultural" (FERNANDES; SAMPAIO, 2012, p. 92). É preciso uma mudança de paradigma que inclua a sustentabilidade socioambiental como elemento essencial ao desenvolvimento (FERNANDES; SAMPAIO, 2012).

Faz-se necessário diferenciar os projetos de desenvolvimento econômico sustentável dos projetos que tentam construir processos de sustentabilidade socioambiental no desenvolvimento. É também na apropriação de conhecimentos e na banalização 
de concepções como o "sustentável" que as forças hegemônicas descritas por Souza (2015) disseminam e mantêm suas lógicas, inclusive no que tange ao pensamento ambiental. Para Leff (2012, p. 24): "Diante da crise ambiental, a racionalidade econômica resiste à mudança, induzindo com o discurso da sustentabilidade uma estratégia de simulação e perversão do pensamento ambiental". Nesse sentido, a reflexão que permeia as discussões sobre sustentabilidade é: até que ponto o desenvolvimento pode ser de fato ambientalmente, socialmente e economicamente sustentável a partir de uma lógica em que a natureza é tratada como mercadoria e cada vez mais acentua-se a desigualdade social?

No escopo das críticas ao desenvolvimento, em que o aspecto econômico parece muitas vezes preponderar sobre todos os outros, está o BemViver. Para Gudynas (2011) um elemento importante do Bem-Viver é o fato de encontrar-se no campo das críticas ao desenvolvimento contemporâneo. A racionalidade do desenvolvimento contemporâneo "sua ênfase nos aspectos econômicos e no mercado, sua obsessão pelo consumo e o mito do progresso ilimitado" são alguns dos questionamentos realizados pelo Bem-Viver (GUDYNAS, 2011, p. 2). Nesta perspectiva, colocada como uma alternativa à ideia de desenvolvimento e não um desenvolvimento alternativo, visa "uma mudança radical no modo como se interpreta e se valoriza a Natureza" que rompe com a concepção antropocêntrica da relação sociedade-natureza. Parte-se também de que no próprio pensamento moderno ocidental, base para a constituição da ideia de desenvolvimento, há abordagens críticas ao desenvolvimento, muitas vezes deixados à margem do pensamento dominante. Para Gudynas (2011, p. 7): "estudos críticos sobre o desenvolvimento, o ambientalismo biocêntrico, o feminismo radical ou a descolonialização do saber" são também formas de buscar o Bem-Viver.

A Educação Ambiental crítica neste trabalho assume o papel de campo articulador entre os debates sobre o ecologismo dos pobres e racismo ambiental e a ideia de desenvolvimento podendo estabelecer relações entre os estudos críticos sobre o desenvolvimento, o ambientalismo o feminismo, desigualdade social e racismo ambiental na perspectiva de uma descolonização dos saberes. A Educação Ambiental em uma perspectiva crítica oferece possibilidades de como trabalhar a questão ambiental em espaços escolares e não escolares para orientar processos de sustentabilidade no desenvolvimento.

$\mathrm{Na}$ próxima seção será apresentado de forma detalhada o ecologismo dos pobres e o movimento por justiça ambiental e dentro deste contexto o racismo ambiental, uma forma de racismo que permeia diversos conflitos socioambientais. Inferese que estas discussões contribuem para uma abordagem crítica da relação sociedade-natureza.

\section{0 ecologismo dos pobres e o racismo ambiental: contribuições para a problematização crítica sobre a relação sociedade-natureza}

Para iniciar esta seção apresenta-se dois casos que apresentam elementos importantes para a discussão proposta. Desde 2012 os moradores da comunidade Quilombola do Abacatal em Belém do Pará vêm sofrendo com os problemas ambientais causados pela construção da Central de Processamento de Tratamentos de Marituba, conhecida pela população como Lixão de Marituba. Trata-se de um aterro sanitário implementado e gerenciado pelas empresas Guama Tratamentos de Resíduos Ltda e Revita Engenharia S.A. Os problemas causados aos moradores do entorno e à comunidade quilombola são vários, dentre eles, cita-se: odor insuportável nas residências oriundo da decomposição e disposição inadequada dos resíduos orgânicos; elevada produção de chorume que está sendo carreado para os cursos de água que não só abastecem a comunidade, como fornecem alimentos; aumento exponencial da demanda nas unidades de saúde por consultas e medicamentos (STEINBRENNER; BRITO; CASTRO, 2020).

O seu Joaquim é quilombola, pertence à Comunidade Remanescente de Quilombos do Varzeão que existe e resiste há mais de duzentos anos no Vale do Ribeira, Paraná. Até 2005, eles não tinham luz elétrica, saneamento básico, políticas de geração de renda, de moradia, saúde e educação. Só conseguiram sobreviver às doenças porque seus ancestrais conheciam os "remédios do mato" que extraíam da Floresta Atlântica, onde a comunidade está incrustada. Acontece que a Floresta Ombrófila Mista que antes ladeava a comunidade quilombola vem sendo paulatinamente substituída por monoculturas de pinus e eucalipto, plantas exóticas, extremamente agressivas ao ambiente. De acordo como os moradores há 50 anos nessa região só 
"havia matão", muitos pinheiros, pássaros e várias outras espécies de animais. Como a flor e o fruto do pinus não servem para alimentar os bichos, eles praticamente desapareceram do local. Os moradores disseram que as empresas foram chegando e comprando pedaços de terra a preço de "banana" ou em alguns casos adquiriram as terras usando os jagunços para expulsar os moradores. Não adiantou reclamar porque as autoridades diziam que as plantações de pinus significavam "desenvolvimento" para a região, pois gerariam renda para a comunidade e para o município. O quilombola pergunta, "desenvolvimento" para quem? A comunidade ficou com os prejuízos ambientais e sociais: erosão dos solos, perda da diversidade e da cultura, diminuição da quantidade de água nos lençóis freáticos, destruição das estradas devido ao constante trânsito de caminhões carregados de madeira, isso só para citar alguns prejuízos. (LOPES, 2010).

$\mathrm{O}$ que essas duas histórias têm em comum? O comum nessas histórias é o fato dessas pessoas serem pobres e negras. Mas as normas programáticas presentes no texto constitucional brasileiro não obrigam as instituições estatais a implementarem medidas para que grupos minoritários possam ter melhores condições de vida? (MOREIRA, 2020). Para entender as duas situações acima é preciso falar de racismo ambiental ${ }^{\mathrm{vi}}$ e das relações entre o modelo econômico de desenvolvimento brasileiro e suas relações com a sociedade e o ambiente (PACHECO; FAUSTINO, 2013). Esse modelo de desenvolvimento tem suas bases fortemente edificadas no projeto colonial que criou a categoria do Outro (denominação criada para representar o negro, indígena e outros) como estratégia de dominação (LANDER, 2005). Dentre os autores que serão utilizados para fundamentar se refletir sobre as relações entre o modelo de desenvolvimento e o racismo ambiental ou justiça ambiental está Joan Martínez Alier, principalmente por meio das discussões proporcionadas pelo seu livro "O ecologismo dos pobres".

A contribuição de Joan Martínez-Alier (2009) em o "O ecologismo dos pobres" para essa reflexão se deve ao fato dele trazer elementos da economia ecológica e da economia política que nos permitem analisar certos conflitos socioambientais como o que aconteceu na comunidade quilombola do seu Manoel e na Comunidade Quilombola do Abacatal à luz da complexidade. Além disso, esta discussão sobre conflitos socioambientais é muito importante para a Educação Ambiental crítica.

A perspectiva de Martínez-Alier (2009) demonstra que no Brasil tais conflitos estão relacionados com a utilização cada vez maior do ambiente natural para subsidiar a expansão econômica:

No Brasil, a exportação de recursos naturais a "preço de banana" ou mesmo a um preço inferior ao das bananas, aumenta a cada ano. A nova fronteira não está mais configurada apenas no ferro de Carajás ou no Alumínio do norte do Pará, mas também na exportação da soja e, em breve, numa maciça exportação de biodiesel. Algumas partes do país "serão transformadas em uma intensa plantação de mamona”. Então o território se ressente, uma vez que está habitado por humanos e por outras espécies. (MARTÍNEZ-ALIER, 2009, p. 14).

Segundo Martínez-Alier (2009), na contemporaneidade três correntes de pensamento dominam o movimento ambientalista mundialmente falando: uma que ele denominou de "O culto ao silvestre", outra que tem predominado nos Estados Unidos e Europa como o "credo da ecoeficiência" e uma terceira corrente, ainda está em construção, conhecida por "justiça ambiental", "ecologismo dos pobres" ou "ecologismo popular".

Vale ressaltar que o autor usa as palavras ambientalismo e ecologismo como sinônimos, embora reconheça em nota de rodapé que os usos dessas palavras variam conforme o país em que estejam sendo usadas. Para Martínez-Alier (2009) foi a expansão do crescimento econômico que impulsionou o crescimento do ambientalismo. Ressalta-se que embora nem todos os ambientalistas sejam contra o crescimento econômico, todos os antiecologistas se opõem às três correntes desqualificando, ignorando ou depreciando-as (TILIO NETO, 2009).

A corrente O "culto ao silvestre" está nos primórdios do movimento ambientalista, surgiu há mais de cem anos nos Estados Unidos e centrou sua atenção na beleza do meio ambiente e na 
ciência ecológica. Seus adeptos se preocuparam em demonstrar as várias funções da natureza como o uso econômico (produção de madeira) e a importância da vida silvestre (MARTÍNEZ-ALIER, 2009). O estereótipo de natureza e meio ambiente como algo separado do ser humano ou "natureza intocada" que permeia grande parte da sociedade brasileira se fundamenta nessa corrente que foi e ainda é enfatizada por programas televisivos como o "Globo Ecologia". Esta vertente dialoga com a macrotendência conservacionista da Educação Ambiental proposta por Layrargues e Lima (2014) conforme será explicitada na próxima seção.

Os adeptos do culto ao silvestre não se contrapõem diretamente ao crescimento econômico, mas defendem que o que resta de natureza no mundo deve ser preservado e mantido fora do alcance do mercado (MARTÍNEZ-ALIER, 2009; TILIO NETO, 2009). A principal proposta política dessa corrente para salvar o que resta da natureza é por meio da preservação ambiental, excluindo as pessoas do processo conservacionista conforme problematizado na seção anterior. O Sistema Nacional de Unidades de Conservação (SNUC) criado no Brasil em 18 de julho de 2000 (BRASIL, 2000) também foi inspirado nessa corrente. O SNUC foi criado para regulamentar o disposto na Constituição Federal Brasileira que estabeleceu que:

Art. 225. Todos têm direito ao meio ambiente ecologicamente equilibrado, bem de uso comum do povo e essencial à sadia qualidade de vida, impondose ao Poder Público e à coletividade o dever de defendê-lo e preservá-lo para as presentes e futuras gerações. (BRASIL, 1988).

Para a garantia deste direito a Constituição estabeleceu que o Poder Público deve:

III - definir, em todas as unidades da Federação, espaços territoriais e seus componentes a serem espacialmente protegidos, sendo a alteração e supressão permitidas somente através de leis, vedada qualquer utilização que comprometa a integridade dos atributos que justifiquem sua proteção. (BRASIL, 1988).

De acordo com a legislação, pode-se inferir que todas as pessoas independentemente de sua condição socioeconômica têm direito a conviver com a natureza, sendo ela bem de uso comum e essencial à qualidade de vida de toda população.

O "culto ao silvestre" ou o "culto ao sagrado", como também é conhecida, tem respaldo científico entre os teóricos da Biologia da Conservação (PRIMACK; RODRIGUES, 2001) ${ }^{\mathrm{vii}}$, sendo a Convenção da Biodiversidade no Rio de Janeiro, ocorrida durante a Rio-92, um dos seus maiores feitos (MARTÍNEZALIER, 2009).

É importante refletir que no Brasil, grande parte das áreas preservadas que foram ou serão transformadas em parques só existem porque foram habitadas e manejadas por comunidades tradicionais, sejam elas indígenas, quilombolas (caso da Comunidade do Varzeão citada no início desta seção), quebradeiras de babaçu e outras. Portanto, parece contraditório querer expulsar essas comunidades desses territórios onde viveram muitas vezes por centenas de anos interagindo e manejando a floresta que a sociedade herdou.

Para Martínez-Alier (2009) a corrente do "culto ao silvestre" interage com uma segunda corrente por ele denominada de "credo ou evangelho da ecoeficiência”. Trata-se de uma escola de pensamento que se diz preocupada com os efeitos do crescimento econômico nas áreas de natureza original, na economia industrial, agrícola e urbana, uma vez que suas ações estão sendo direcionadas para os impactos ambientais e riscos à saúde oriundos tanto de atividades industriais, urbanização e agricultura moderna (MARTÍNEZ-ALIER, 2009; TILIO NETO, 2009). Diz respeito a um movimento que não acredita no desenvolvimento a qualquer custo, e realiza a defesa de perspectivas como "desenvolvimento sustentável”, a "modernização ecológica" e a correta utilização dos recursos (MARTÍNEZ-ALIER, 2009).

Para Acselrad (2002), para combater o desperdício de energia, considerada pelos economistas como o principal problema ambiental, os governos têm proposto ações de "modernização ecológica" com a intenção exclusiva de manter a eficiência sem prejudicar o mercado. São ações tomadas do ponto de vista da lógica econômica que delegam ao mercado 
a resolução dos problemas de degradação ambiental, inclusive abrindo espaços para negócios na área das "tecnologias limpas". Estas premissas marcam o Evangelho da Ecoeficiência discutido por MartínezAlier (2009), o próprio mercado que ocasiona a degradação ambiental teria soluções para mitigá-lo. Assim, reduz-se a questão ambiental a uma questão de progresso e eficiência tecnológica. Possivelmente ambientalistas desta corrente, preocupados com a grave crise hídrica e energética que estamos vivendo no Brasil nesse momento defenderiam que a sociedade deve encontrar formas de produzir alimentos usando técnicas menos agressivas e impactantes ao ambiente e que consumam menos água. De acordo com a FAO (2018) "A agricultura é a principal usuária dos recursos hídricos disponíveis, uma média de $70 \%$ do consumo mundial." Segundo o relatório da Agência Nacional de Águas de 2012 (ANA, 2012), a maior vazão de água consumida no Brasil, 72\%, foi para a irrigação. Em 2018 a média anual de água consumida para irrigação no Brasil foi de $66,1 \%$ (ANA, 2019) ${ }^{\text {viii }}$.

Cabe ressaltar que dentre que os defendem a modernização ecológica (ambientalistas conservadores ou empresários) não há nenhuma tentativa de refletir sobre os problemas sociais que a degradação ambiental pode causar, como por exemplo, o vínculo entre degradação ambiental e injustiça social (ACSELRAD, 2002), assunto que será discutido mais adiante.

O que se problematiza neste ensaio é que os problemas ambientais são também socioambientais. Qual seria então o papel da modernização ecológica na resolução dos problemas sociais? No bojo da modernização ecológica constituem-se concepções como o mecanismo de desenvolvimento limpo (MDL) (LAZARO; GREMAUD, 2017) e os cinco Rs - repensar, reduzir, recusar, reutilizar e reciclar a produção de resíduos, perspectiva amplamente propalada em perspectivas conservadoras de Educação Ambiental durante a educação básica. Estas concepções podem levar a uma ideia equivocada de que seria possível resolver os problemas socioambientais a partir da mudança de comportamento individual, fechando as torneiras enquanto se escovam os dentes, diminuindo o tempo de banho, reciclando ou reutilizando embalagens. Porém, entende-se que o problema é muito mais complexo à medida que as grandes propriedades agrícolas e o agronegócio continuam produzindo commodities e utilizando grandes volumes de água.

Voltando aos casos trazidos no início da seção: como a plantação de pinus no entorno da Comunidade Quilombola do Varzeão, diminuiu a pressão sobre Floresta Atlântica, floresta de onde os quilombolas vêm retirando seus remédios e alimentos por mais de duzentos anos para conseguirem sobreviver a falta de políticas de saúde e geração de renda? Ao contrário do que dizem as duas correntes supracitadas, a pressão sobre o ecossistema onde vivem os quilombolas aumentou à medida que extensas áreas de florestas foram substituídas pela monocultura de pinus que praticamente acabou com a biodiversidade local, contaminou a água dos rios e secou as nascentes, tornando a água cada vez mais escassa (LOPES, 2010).

É possível perceber que nem o "culto ao silvestre" e nem o "credo à ecoeficiência" parecem contemplar totalmente os anseios das comunidades e/ou povos tradicionais. Nesse contexto é que se apresenta uma terceira corrente, denominada por Martínez-Alier (2009) de "ecologismo dos pobres", "ecologismo popular" ou "movimento de justiça ambiental". Essa corrente particularmente interessa ao debate estabelecido neste ensaio porque dialoga diretamente com a Educação Ambiental crítica e aponta que o crescimento econômico não só gera impactos ao meio ambiente, como também destaca o deslocamento geográfico das fontes de recursos e do descarte dos resíduos para locais onde vivem comunidades tradicionais e/ou periferias habitadas por pessoas pobres.

É interessante notar que muitos dos grupos atingidos pelo modelo de desenvolvimento econômico atual o precisam reivindicar seu espaço de direito ao território remetendo a sacralidade de suas áreas na tentativa de defender seu sustento e sua reprodução social (MARTÍNEZ-ALIER, 2009; 2015). Portanto, não compartilham dos mesmos fundamentos éticos e nem estéticos da corrente do "culto ao silvestre" porque "sua ética nasce de uma demanda por justiça social" (MARTÍNEZ-ALIER, 2009, p. 34).

A corrente do ecologismo dos pobres tem chamado a atenção para o fato de se levar em consideração a contribuição que tanto indígenas, camponeses, quilombolas e outras comunidades tradicionais terem "co-evolucionado sustentavelmente com a natureza, assegurando assim a conservação da 
biodiversidade" (MARTÍNEZ-ALIER, 2009, p. 34). Estes pressupostos são evidenciados por autores como Toledo e Barrera-Bassols (2015) nos estudos sobre o campesinato e sua relação com o meio natural apresentado o conceito de Memória Biocultural. Autores como Gómez-Pompa e Kaus (2000) afirmam que muitas vezes as concepções ocidentais de conservação da natureza não dialogam com as comunidades rurais. A própria ideia de ecossistemas naturais intocados é considerada "fruto de uma percepção urbana, da visão de pessoas muito afastadas do meio ambiente natural" (GÓMEZPOMPA; KAUS, 2000, p. 129).

Enquanto os defensores da corrente o "credo da ecoeficiência" confiam no mercado para resolver os problemas ambientais, os defensores do "ecologismo dos pobres" procuram demonstrar que há uma relação entre injustiça social e/ou ambiental e os problemas socioambientais. Para Acselrad (2002, p. 51) os atores sociais que evidenciam a relação entre a injustiça social e a degradação ambiental "consideram que há clara desigualdade social na exposição aos riscos ambientais, decorrente de uma lógica que extrapola a simples racionalidade abstrata das tecnologias". Sob esta ótica, o enfrentamento da degradação ambiental é também momento de "ganhos de democratização e não apenas de ganhos de eficiência e ampliação de mercado" (ACSELRAD, 2002, p. 51).

É neste escopo que nasce a luta por justiça ambiental nos Estados Unidos na década de 1960 (ACSELRAD, 2002). A luta por justiça ambiental evidencia a situação de diversas comunidades do campo e da cidade que vivem em regiões atingidas por impactos ambientais e em condições inadequadas de moradia. Para Acselrad (2002, p. 52) "redefiniuse em termos "ambientais" um conjunto de embates contra as condições inadequadas de saneamento, de contaminação química de locais de moradia e trabalho e disposição indevida de lixo tóxico e perigoso". A partir dos anos de 1970, as pautas dos sindicatos que estavam preocupadas com a saúde ocupacional de minorias étnicas, incorporaram as "questões ambientais urbanas". $\mathrm{Na}$ época já existiam pesquisas que indicavam haver relação entre a distribuição espacial desigual da poluição de acordo com a raça das pessoas. O próximo passo foi lutar para que a pauta das entidades ambientalistas reivindicasse o combate à disposição inadequada de resíduos tóxicos perigosos em áreas onde residiam populações negras (ACSELRAD, 2002).
No Brasil, os conflitos socioambientais bem como as injustiças ambientais impactam principalmente as populações mais vulneráveis socialmente, com características étnicas pertencente aos negros ou indígenas. É por isso que a reflexão sobre as questões socioambientais deve incluir o conceito de racismo ${ }^{\text {ix }}$ principalmente porque o modelo desenvolvimento, que contribuiu para os conflitos socioambientais e pelas injustiças ambientais remonta o Brasil colônia (PACHECO; FAUSTINO, 2013).

Antes de se refletir sobre o racismo ambiental que algumas comunidades tradicionais, como as quilombolas e indígenas têm sofrido no Brasil, considera-se importante trazer um pouco do histórico do termo 'racismo ambiental'. A primeira pessoa a utilizar essa expressão pela primeira vez foi o químico e reverendo Benjamim Chavis, durante uma luta pelos direitos civis em Warren County, nos Estados Unidos. Ele chegou publicar um estudo intitulado Toxic Waste and Race in the United States of America, em que demonstrou a gravidade dos rejeitos tóxicos que eram depositados inadequadamente no entorno nas comunidades negras nos Estados Unidos (PACHECO; FAUSTINO, 2013). Além de Chavis, o sociólogo Robert Bullard, em 1993, escreveu o livro Confronting Environmental Racism: voices from the grassroots que foi muito importante no enfrentamento do racismo ambiental e da injustiça ambiental nos Estados Unidos e no mundo (PACHECO; FAUSTINO, 2013). Mais recentemente Martínez-Alier (2009), no livro O ecologismo dos pobres, ao abordar o racismo ambiental nos países em desenvolvimento, credita o nascimento desse movimento por justiça ambiental aos Estados Unidos (PACHECO; FAUSTINO, 2013).

No que diz respeito ao racismo ambiental no contexto brasileiro, para Pacheco e Faustino (2013, p. 74), "é preciso reconhecer a questão racial e o etnocentrismo como problemas centrais do cenário brasileiro no qual se inserem os grupos sociais envolvidos nos conflitos" As autoras evidenciam que no caso brasileiro é preciso ter em consideração o processo histórico colonial. Na realidade brasileira a constituição das elites, a distribuição do poder e riqueza, e assim, das classes sociais, são permeadas pelas desigualdades étnicas e também raciais (PACHECO; FAUSTINO, 2013). Assim, neste ensaio, quando se infere a necessidade de um debate ambiental que tenha em conta e dialogue com a desigualdade social, também inclui-se a desigualdade 
étnica e racial. A análise das autoras insere mais um importante olhar à questão ambiental brasileira ao afirmar que:

O caráter etnocentrista da formação da nação brasileira também ajuda a entender por que, nos dias atuais, os povos indígenas e as comunidades tradicionais são considerados e tratados como atrasados e estão fadados à transição para a cultura e os modelos desenvolvimentistas que marcam o capitalismo no seu estágio atual. (PACHECO; FAUSTINO, 2013, p. 77).

O que Martínez-Alier (2009) apresenta como ecologismo dos pobres dialoga com a perspectiva destas autoras. O debate sobre a relação sociedadenatureza a partir de uma perspectiva crítica precisa incluir um olhar socioambiental que dialogue com as sabedorias sustentáveis dos povos indígenas e das comunidades tradicionais nos projetos de conservação ambiental no atual modelo de desenvolvimento.

Por fim, o debate sobre os conflitos socioambientais que atingem comunidades tradicionais no Brasil, seja por sua vulnerabilidade social, seja por questões étnicas e raciais, precisam ser abordados também do ponto de vista do racismo ambiental e do movimento por justiça social e ambiental para uma Educação Ambiental crítica nos espaços escolares e não escolares, porque essa posição vulnerável, na maioria das vezes, resulta do processo de hierarquização de pessoas a partir do seu fenótipo. A subalternização de pretos, pardos e indígenas foi umas das estratégias usadas no colonialismo que foi ressignificada e contínua presente até hoje em nossa sociedade.

Na próxima seção será apresentada a perspectiva da Educação Ambiental crítica como campo articulador entre as problematizações trazidas no ecologismo dos pobres e no racismo ambiental. Estas problematizações são essenciais para a análise sobre a relação sociedade-natureza na Educação Ambiental a partir de uma abordagem crítica.
5 A educação ambiental crítica como espaço de diálogo sobre a relação sociedade-natureza

De acordo com a Política Nacional de Educação Ambiental considera-se Educação Ambiental:

Art. $1[\ldots]$ os processos por meio dos quais o indivíduo e a coletividade constroem valores sociais, conhecimentos, habilidades, atitudes e competências voltadas para a conservação do meio ambiente, bem de uso comum do povo, essencial à sadia qualidade de vida e sua sustentabilidade. (BRASIL, 1999).

Esse processo envolve "todos os níveis e modalidades do processo educativo, em caráter formal e não-formal" (BRASIL, 1999). Assim, entende-se a Educação Ambiental, como um campo de estudos e de práticas que orienta a construção de valores socioambientais em espaços escolares e não escolares. A Educação Ambiental deve extrapolar os ambientes formais de educação, devendo estar presente em toda relação sociedade-natureza.

Layrargues e Lima (2014) mapearam as macrotendências político-pedagógicas da Educação Ambiental. Os autores afirmam que em um momento inicial a Educação Ambiental tinha um viés essencialmente conservacionista (LAYRARGUES; LIMA, 2014). Com o passar do tempo esta perspectiva foi deixando de ser a mais recorrente e alguns educadores foram se aproximando mais de perspectivas críticas, outros mais pragmáticas (LAYRARGUES; LIMA, 2014). Segundo os autores, nos de 1990 os educadores que compartilhavam uma concepção socioambiental começaram a diferenciar as propostas de Educação Ambiental em conservadora e alternativa. No âmbito conservador identificam-se as abordagens conservacionistas e pragmáticas, já no alternativo a concepção crítica (LAYRARGUES; LIMA, 2014). A opção conservadora parte do "[...] predomínio de práticas educativas que investiam em crianças nas escolas, em ações individuais e comportamentais no âmbito doméstico e privado, de forma a-histórica, apolítica, conteudística e normativa não superariam o paradigma hegemônico [...]" (LAYRARGUES; LIMA, 2014, p. 29). Nesta concepção o ser humano é tratado como um "ente genérico e abstrato" reduzido 
a causador da crise ambiental, desconsiderando dimensões sociais, econômicas da vida em sociedade (LAYRARGUES; LIMA, 2014, p. 29).

A crítica apresentada por Layrargues e Lima (2014) vem ao encontro da perspectiva apresentada neste ensaio, da necessidade de um olhar sobre a relação sociedade-natureza para além da ideia de um ser humano causador da crise ambiental. Guimarães (2013) problematiza essa perspectiva individual e comportamentalista da Educação Ambiental em que o ensinamento sobre os comportamentos considerados corretos seriam suficientes para que os indivíduos adquirissem tais comportamentos, sendo assim, em uma perspectiva de transmissão de convenções. A culpabilização da humanidade pela crise ambiental reduz o debate a algo inevitável, a uma essencialidade da espécie em causar degradação. Nesta perspectiva, exime-se do debate o fato de que se vive em uma sociedade e que, ainda que se compartilhe de certas ideias que são preponderantes na sociedade moderna ocidental, ainda assim, ela é heterogênea, com uma diversidade de povos e grupos sociais nos mais diversos territórios, empreendendose as mais diversas relações com a natureza, sendo que em muitos casos, sustentáveis. Para a formação de educadores críticos que contextualizem o debate socioambiental na desigualdade social e a partir de um pensamento ambiental crítico é preciso um processo de formação que incorpore perspectivas teóricas analíticas que deem conta da interdisciplinaridade e complexidade do debate.

Além da desigualdade social, infere-se a necessidade da inserção da análise sobre a desigualdade étnica e racial apresentada por Pacheco e Faustino (2013). Estas desigualdades permeiam os conflitos socioambientais. Segundo Pacheco e Faustino (2013, p. 78) "A literatura sobre as injustiças ambientais é particularmente enfática [...] na constatação de que tais injustiças são marcadas por um forte enlace com as desigualdades sociais, políticas, econômicas e culturais."

Partindo-se da necessidade de olhares teóricos que deem conta da análise da problemática socioambiental na Educação Ambiental, Layrargues e Lima (2014, p. 29) apontam as influências do pensamento de Paulo Freire, "da Educação Popular, da Teoria Crítica e da Ecologia Política" como influências da perspectiva crítica da Educação Ambiental. Neste ensaio, afirma-se também a contribuição também do debate teórico do ecologismo dos pobres e/ou movimento por justiça ambiental e do racismo ambiental e a potencialidade destas abordagens na construção da Educação Ambiental crítica.

Loureiro e Layrargues (2013) reforçam a importância da luta social e a necessidade de "processos de superação das relações sociais alienadas destrutivas da natureza", além do foco na materialidade e no debate sobre classe, presentes na Ecologia Política (LOUREIRO; LAYRARGUES, 2013, p. 53). Conforme já argumentado, é preciso situar a problemática socioambiental em um debate mais amplo sobre sociedade, sobre processos de desenvolvimento e de desigualdade social.

Considera-se a importância das abordagens conservacionistas e pragmáticas da Educação Ambiental pelas possíveis contribuições destas perspectivas nos seguintes aspectos: da perspectiva conservacionista para orientar a formação de uma ética ambiental que considere também a conservação da natureza pelo seu valor de existência e contribuição nas relações ecológicas e não apenas pela forma como pode servir ou influenciar a vida humana; na perspectiva pragmática - na problematização sobre as lógicas e os hábitos de consumo da sociedade moderna ocidental e a necessidade de uma atenção ao papel de cada indivíduo, mas incluindo-se também dos setores econômicos na construção de uma sociedade social e ambientalmente saudável.

Entende-se que estes debates precisam estar contextualizados na realidade, nas relações sociais e na emancipação humana. O debate deve estenderse envolvendo a contribuição das pessoas também para a construção de uma sociedade mais justa e equitativa, envolvendo os conflitos socioambientais, a desigualdade social e a discriminação sofrida por diversos povos. Há a discriminação ambiental, sofrida por povos etnicamente e culturalmente diferenciados, e/ou em função de sua vulnerabilidade socioeconômica e como estes aspectos refletem na injustiça ambiental sofrida por eles. Este debate permeia o que se tratou no ecologismo dos pobres e/ ou movimento por justiça ambiental e o debate sobre racismo ambiental.

Infere-se que as abordagens que reforçam o que Layrargues e Lima (2014, p. 29) trataram como "paradigma hegemônico que tende a tratar o ser humano como um ente genérico e abstrato, reduzindo-os à condição de causadores da crise ambiental", são abordagens que reforçam um pensamento ambiental que não considera a realidade 
e o contexto de diversos grupos sociais. Muitas vezes, os debates superficiais em Educação Ambiental centrados no comportamento das pessoas e, portanto, em um debate socioambiental focado no indivíduo e/ ou na espécie humana e não na sociedade, parecem não considerar debates importantes como classe, o feminismo, as relações étnico-raciais, a desigualdade social, a inclusão, dentre tantos outros. Reforça-se o papel da Educação Ambiental crítica no diálogo sobre a relação sociedade-natureza que contribua para a transformação da relação entre as pessoas e consequentemente entre as pessoas na natureza.

\section{Considerações finais}

Este texto teve como objetivo apresentar a contribuição do ecologismo dos pobres e do racismo ambiental para a construção de uma perspectiva crítica do pensamento ambiental na relação sociedade-natureza na Educação Ambiental. Partiu-se de uma problematização sobre a crise ambiental, sobre a relação sociedade-natureza sobre o desenvolvimento e o Bem-Viver como perspectiva crítica do desenvolvimento. Argumentou-se os aspectos do ecologismo dos pobres e do racismo ambiental como forma de reorientar o debate socioambiental localizando o ser humano na natureza e a necessidade de que o debate ambiental seja tratado a partir da problemática socioambiental envolvendo a discriminação das comunidades no campo e na cidade e a desigualdade social, étnica e racial e sua relação com os conflitos socioambientais. A Educação Ambiental crítica é apontada como um campo importante para tais discussões. Para tal recomenda-se que: os projetos em Educação Ambiental crítica evidenciem os conflitos socioambientais e as contradições enfrentadas pelas comunidades no campo e na cidade.

Os projetos precisam trazer para o debate nos ambientes escolares e não escolares, temas como a desigualdade social, étnica e racial e como a compreensão sobre a situação e sobre as causas dessas desigualdades contribuem para a compreensão da problemática ambiental. São necessários educadores e educadoras ambientais que compreendam as causas da crise ambiental, educando para a análise crítica da sociedade e para a transformação social, compreendendo o ser humano como parte da natureza. A relação que as pessoas têm com os demais seres vivos, com o solo, com a água, com os elementos minerais, são reflexos das relações sociais. Assim, para que haja a transformação da relação sociedade-natureza para a sustentabilidade é preciso também a transformação das relações sociais e de poder na sociedade.

\section{Referências}

AGÊNCIA NACIONAL DE ÁGUAS (Brasil) ANA. Conjuntura dos recursos hídricos no Brasil: informe 2012. Ed. Especial. Brasília: ANA, 2012. Disponível em: <https://arquivos.ana.gov.br/ imprensa/arquivos/Conjuntura2012.pdf $>$

AGÊNCIA NACIONAL DE ÁGUAS (Brasil) ANA. Conjuntura dos recursos hídricos no Brasil 2019: informe anual. Brasília: ANA, 2019. Disponível em: <http://conjuntura.ana.gov.br/static/ media/conjuntura-completo.bb39ac07.pdf $>$

ACSELRAD, H. Justiça Ambiental e construção social do risco. Desenvolvimento e Meio Ambiente, Curitiba, n. 5, p. 49-60, jan./jun. 2002.

BARROS, A. Desemprego recua para $14,1 \%$ no $2^{\circ}$ tri, mas ainda atinge $\mathbf{1 4 , 4}$ milhões de pessoas. PNAD Contínua. Agência IBGE Notícias, 31 ago. 2021. Disponível em: $<$ https://agenciadenoticias.ibge. gov.br/agencia-noticias/2012-agencia-de-noticias/ noticias/31480-desemprego-recua-para-14-1-no-2tri-mas-ainda-atinge-14-4-milhoes-de-pessoas $>$

BRASIL. Presidência da República. Casa Civil. Constituição da República Federativa do Brasil de 1988. Disponível em: <https://www.planalto.gov.br/ ccivil 03/constituicao/constituicao.htm $>$

BRASIL. Presidência da República. Casa Civil. Lei no. 9.795 de 27 de abril de 1999. Dispõe sobre a educação ambiental, institui a Política Nacional de Educação Ambiental e dá outras providências. Disponível em: <https://www.planalto.gov.br/ ccivil_03/leis/19795.htm>

BRASIL. Presidência da República. Casa Civil. Lei $n^{\circ} .9 .984$ de 18 de julho de 2000. Regulamenta o art. 225, § 1o, incisos I, II, III e VII da Constituição Federal, institui o Sistema Nacional de Unidades de Conservação da Natureza e dá outras providências. Disponível em: <https://www.planalto.gov.br/ ccivil_03/leis/19985.htm>

BRASIL. Presidência da República. Casa Civil. Decreto 6.040 de 7 de fevereiro de 2007. Institui a Política Nacional de Desenvolvimento Sustentável dos Povos e Comunidades Tradicionais. Brasília, DF, 2007. 
BRASIL DE FATO. Quem são os bilionários brasileiros que seguem na lista da Forbes apesar da pandemia. Enquanto 19 milhões passam fome, número de bilionários saltou de 45 para 65 , com aumento de $71 \%$ na soma das riquezas. Geral. Desigualdade. 07 abr. 2021. Disponível em: <https:// www.brasildefato.com.br/2021/04/07/quem-saoos-bilionarios-brasileiros-que-seguem-na-lista-daforbes-apesar-da-pandemia $>$

BRESSER-PEREIRA, L. C. Desenvolvimento, progresso e crescimento econômico. Lua Nova, São Paulo, n. 93, p. 33-60, 2014.

DIEGUES, A.C.; ARRUDA, R. S. V.; SILVA, V. C. F.; FIGOLS, F. A. B.; ANDRADE, D. Os Saberes Tradicionais e a Biodiversidade no Brasil. São Paulo: NUPAUB/USP, PROBIO/MMA, CNPq, 2000. Disponível em: <http://livroaberto.ibict. $\mathrm{br} /$ bitstream $/ 1 / 750 / 2 /$ Biodiversidade $\% 20 \mathrm{e} \% 20$ comunidades $\% 20$ tradicionais $\% 20$ no\%20Brasil.pdf $>$

DIEGUES, A. C.; NOGARA, P. J. N. O nosso lugar virou parque: estudo socioambiental do Saco de Mamanguá - Parati - Rio de Janeiro. São Paulo: NUPAUB-USP, 2005.

DUPAS, G. O mito do progresso. Novos estudos, São Paulo, n .77, p. 73-89, mar. 2007.

FAO. Food and Agriculture Organization. FAO e CNA lançam estudo sobre agricultura irrigada brasileira. FAO no Brasil. 16 mar. 2018. Disponível em: <https://www.fao.org/brasil/noticias/detailevents/pt/c/1107498/>

FERRARI, H. Brasil cai para $13^{\circ}$ no ranking de maiores economias, diz Austin Rating. Poder 360, 01 jun. 2021. Disponível em: $<$ https://www.poder360. com.br/economia/brasil-cai-para-13o-no-rankingde-maiores-economias-diz-austin-rating/>

FERREIRA, M. R. A construção do conhecimento em Ciências Ambientais: contribuições da abordagem decolonial. In: SGUAREZI, S. B. Ambiente e Sociedade no Brasil Central: Diálogos Interdisciplinares e Desenvolvimento Regional. São Leopoldo: Oikos; Cáceres: Editora UNEMAT, 2019. p. 14-27.

FERNANDES, V.; SAMPAIO C. A. C. Problemática ambiental ou problemática socioambiental? Desenvolvimento e Meio Ambiente, Curitiba, n. 18, p. 87-94, jul./dez. 2008.
GERBELLI, L. G. Crise hídrica se agrava e vira mais um entrave para o crescimento da economia brasileira. G1 Economia. Crise da Água, 01 set. 2021. Disponível em: <https:/g1.globo.com/ economia/crise-da-agua/noticia/2021/09/01/crisehidrica-se-agrava-e-vira-mais-um-entrave-para-ocrescimento-da-economia-brasileira.ghtml>

GÓMEZ-POMPA, A.; KAUS, A. Domesticando o Mito da Natureza Selvagem. In: DIEGUES, A. C. S. (Org.) Etnoconservação: novos rumos para a conservação da natureza, São Paulo: Hucitec/ Annablume/Nupaub-USP, 2000.

GONÇALVES, R. J. A. F. Conflitos ambientais territoriais em Comunidades Camponesas impactadas por grandes projetos de extrativismo mineral em Catalão, Goiás. Revista Territorial, v. 4, n. 1, p. 66-81, 2015.

GUDYNAS, E. Bem Viver: Germinando alternativas ao desenvolvimento. 2011. Disponível em: <http://www.mobilizadores.org.br/wpcontent/uploads/2014/05/bem-viver_-germinandoalternativas-ao-desenvolvimento.pdf $>$

GUIMARÃES, M. Por uma educação ambiental crítica na sociedade atual. Margens, Abaetetuba, v. 7, n. 9, p. 11-22, 2013.

LANDER, E. Ciências sociais: saberes coloniais e eurocêntricos. In: LANDER, E. A colonialidade do saber: eurocentrismo e ciências sociais, perspectivas latino-americanas. Buenos Aires, Consejo Latinoamericano de Ciências Sociais, 2005.

LAZARO, L. L. B.; GREMAUD, A. P. Contribuição para o desenvolvimento sustentável dos projetos de mecanismos de desenvolvimento limpo na América Latina. Organizações \& Sociedade, Salvador, BA, v. 24, n. 80, p. 53-72, jan./mar. 2017.

LAYRARGUES, Philippe Pomier; LIMA, Gustavo Ferreira da Costa. As Macrotendências PolíticoPedagógicas da Educação Ambiental Brasileira. Ambiente \& Sociedade. São Paulo v. XVII, n. 1, p. 23-40, 2014. Disponível em: https://www. scielo.br/j/asoc/a/8FP6nynhjdZ4hYdqVFdYRtx/ ?format $=$ pdf\&lang $=\mathrm{pt}$

LEFF, E. Saber ambiental: sustentabilidade, racionalidade, complexidade, poder. Petrópolis, RJ: Vozes, 2012 
LOPES, C. V. G. O conhecimento etnobotânico da comunidade quilombola do varzeão, dr Ulysses (PR): no contexto do desenvolvimento rural sustentável. 162f. Tese (Doutorado em Ciências) - Setor de Ciências do Solo, Departamento de Fitotecnia, Universidade Federal do Paraná, Curitiba, 2010 .

LOUREIRO, Carlos Frederico B.; LAYRARGUES, Philippe Pomier. Ecologia política, justiça e educação ambiental crítica: perspectivas de aliança contra hegemônica. Trab. Educ. Saúde, Rio de Janeiro, v. 11, n. 1, p. 53-71, jan./abr., 2013.

MARTÍNEZ-ALIER, J. O ecologismo dos pobres. São Paulo: Contexto, 2009.

MARTÍNEZ-ALIER, J. Ecologismo dos pobres, colonialidade e metabolismo social. Entrevista concedida a Felipe Milanez. Revista InSURgência, Brasília, ano 1, v.1, n.2, p.8-18, 2015.

MOREIRA, A. J. Tratado de direito antidiscriminatório. São Paulo: Editora Contracorrente, 2020.

MOTA, K. DETER/INPE confirma recorde de desmatamento em maio: $67 \%$ de aumento. Dados do sistema DETER, do Instituto de Pesquisas Espaciais (Inpe), divulgados hoje comprovam que os alertas de desmatamento na Amazônia não param de crescer. 11 jun. 2021. Disponível em: $<$ https://www.ecodebate. com.br/2021/06/11/deterinpe-confirma-recorde-dedesmatamento-em-maio-67-de-aumento/>

PACHECO, T. "Racismo Ambiental: o que eu tenho a ver com isso?" Combate Racismo Ambiental, 2014?. Disponível em: $<$ https://racismoambiental.net. br/racismo-ambiental-o-que-eu-tenho-a-ver-comisso/>

PACHECO, T.; FAUSTINO, C. A Iniludível e Desumana Prevalência do Racismo Ambiental nos Conflitos do Mapa. In: PORTO, M. F.; PACHECO, T.; LEROY, J. P. (Org.). Injustiça ambiental e saúde no Brasil: o Mapa de Conflitos. Rio de Janeiro: Editora FIOCRUZ, 2013. p. 73-114. Disponível em: <http://books.scielo.org/id/468vp/pdf/ porto-9788575415764-04.pdf>

${ }^{\text {i }}$ De acordo com Tilio Neto (2009) o termo Ecologismo dos Pobres é de 1988, tendo sido sugerido por Alberto Flores Galindo, mas foi Martínez-Alier quem o popularizou.
PRIMACK, Richard B.; RODRIGUES, Efraim. Biologia da Conservação. Londrina: E. Rodrigues, 2001.

REDE BRASILEIRA DE PESQUISA EM SOBERANIA E SEGURANÇA ALIMENTAR E NUTRICIONAL - REDE PENSSAN. VIGISAN Inquérito Nacional sobre Insegurança Alimentar no Contexto da Pandemia da Covid-19 no Brasil. 2021. Disponível em: <http://olheparaafome.com.br/ VIGISAN_Inseguranca_alimentar.pdf $>$

SOUZA, F. A. C. A relação natureza-sociedade no modo de produção capitalista. Em Pauta, Rio de Janeiro, v. 13, n. 35, p. 153-168, 2015.

STEINBRENNER, R. M. A.; BRITO, R. S.; CASTRO, E. R. Lixo, racismo e injustiça ambiental na Região Metropolitana de Belém. Caderno Metropolitano, São Paulo, v. 22, n.49, p. 935-961, 2020.

TILIO NETO, Petrônio de. Ecopolítica das mudanças climáticas: o IPCC e o Ecologismo dos pobres. São Paulo: Plêiade, 2009. Disponível em: https://www5.pucsp.br/ecopolitica/downloads/ liv_2009_Ecopolitica_Mudancas_Climaticas_IPCC. pdf Acesso em: 16 out. 2021.

TRISTÃO, M.; VIEIRAS, R. R. Decolonizar o pensamento: apontamentos e entrelaçamentos epistêmicos com a Educação Ambiental. Rev. Eletrônica Mestr. Educ. Ambient., Rio Grande, Edição especial XVI Encontro Paranaense de Educação Ambiental, p. 103-117, set. 2017.

ZHOURI, A.; LASCHEFSKI, K. Conflitos Ambientais. 2010. Disponível em: <https:// conflitosambientaismg.lcc.ufmg.br/wp-content/ uploads/2014/04/ZHOURI_LASCHEFSKI_-_ Conflitos_Ambientais.pdf $>$

\footnotetext{
ii Os conflitos distributivos são oriundos das desigualdades sociais no acesso e utilização dos recursos naturais. Os espaciais são gerados a partir dos impactos ambientais que vão além dos limites entre os territórios de determinados grupos sociais. Os territoriais são gerados a partir da apropriação capitalista dos territórios de grupos sociais (ZHOURI; LASCHEFSKI, 2010). "Os conflitos ambientais
} 
territoriais são compreendidos a partir da sobreposição de reivindicações e interesses de grupos sociais distintos, portadores de identidades e lógicas culturais e socioeconômicas também diferenciadas, sobre o mesmo recorte espacial" (GONÇALVES, 2015, p. 73).

iii Entende-se a importância e a necessidade das ações de preservação ambiental, por exemplo na proteção de espécies endêmicas e ambientes naturais fragilizados, porém partese de que não são as ações pontuais em si, e sim a lógica que opera por trás dela, que precisam ser revistas de forma que possam contribuir para a conservação ambiental visto o atual cenário da crise ambiental que se vive no Brasil.

iv Para Bresser-Pereira (2014, p. 34) "[...] a ideia de desenvolvimento surgiu como substituta ou nova designação para o progresso, agora com forte viés econômico".

v O dado publicado pelo Brasil de Fato se refere ao informado pela Forbes em relação aos bilionários domiciliados no Brasil.

vi [...] é a discriminação racial nas políticas ambientais. É discriminação racial no cumprimento dos regulamentos e leis. É discriminação racial no escolher deliberadamente comunidades de cor para depositar rejeitos tóxicos e instalar indústrias poluidoras. É discriminação racial no sancionar oficialmente a presença de venenos e poluentes que ameaçam as vidas nas comunidades de cor. E discriminação racial é excluir as pessoas de cor, historicamente, dos principais grupos ambientalistas, dos comitês de decisão, das comissões e das instâncias regulamentadoras (CHAVIS, 1993, p. 3, apud PACHECO; FAUSTINO, 2013).

vii A Biologia da Conservação parte do princípio de que é preciso entender os efeitos das atividades humanas na natureza e então desenvolver abordagens práticas que mantenham as espécies e as reintegre em seus ecossistemas (PRIMACK; RODRIGUES, 2001).

viii A agroecologia a partir de seus princípios e da produção de base ecológica é entendida como um contraponto a este modelo.

ix Trata-se de uma prática social que hierarquiza os indivíduos e grupos sociais por meio da racialização. (PACHECO; FAUSTINO, 2013). 